\title{
An Introduction to Mechanical Engineering Program for Middle School Students
}

\author{
Craig W. Somerton, Terry L. Ballinger \\ Michigan State University/Lansing Catholic Central High School
}

\section{Introduction}

The Mathematics, Science, and Technology (MST) program at Michigan State University is a two week, summer residential program for academically talented middle school students. This past summer, for the first time, a mechanical engineering academic class was offered. The students attend the class for two hours each day. An MSU faculty member is paired with a local middle or high school teacher for each academic class. The mechanical engineering class was divided into ten units, coinciding with the ten class periods. Each unit covered one of the basic topics of mechanical engineering. The standard format of a class period involved three components. First, a relatively brief lecture was given on the topic of the day. This was done using a Microsoft PowerPoint slide show, which conveyed a certain level of professionalism in the class and the use of technology. The second part of the class period involved a hands-on project. The project tied in with the topic of the day and was of such a form that the students could test their projects against each other in a competition. Finally, the class period concluded with a review of the project, including an assessment as to why certain devices performed better than other devices. Approximately half of the units included a homework assignment that involved calculations associated with the project.

The topics presented in the class were identified through input gathered from faculty in the Department of Mechanical Engineering at MSU. The following nine topics were then incorporated in the course:

Energy, Work and Heat

Structures

Heating and Air Conditioning

Dynamics

Manufacturing
Design as a Creative Problem Solving Process Buoyancy and Aerodynamics

Propulsion

Controls

Since the first class period was devoted to an introduction of the profession of engineering (and mechanical engineering in particular), nine class periods were left to cover the nine topics listed above. However, it seemed necessary to pair one of the technical topics with the design topic, as it would be difficult to introduce the creative problem solving process we call design without a problem to focus on. Structures was chosen as the technical topic to be paired with the design topic. Two tours were also included in the program. The first tour was a tour of the HVAC facilities in the MSU Engineering Building (where the class was held), and replaced the handson project component for the heating and air conditioning unit. A tour of the General Motors final assembly plant in Lansing was used as part of the manufacturing unit. With the required 
travel time, this tour used all two hours of class time. It was decided that two class periods should be devoted to the manufacturing topic. The first of these class periods would follow the standard format (lecture, project, wrap-up) and the second class period would be the tour of the General Motors plant. This paper continues with a detailed description of each unit that includes a summary of the lecture, description of the hands-on project, the homework assignment, and lessons learned.

\section{Description of Units}

\section{Unit 1 - Introduction to Mechanical Engineering}

Lecture Summary: This unit had one of the longer lectures (about 45 minutes) as students were introduced to the engineering profession and, specifically, mechanical engineering. Operational definitions were given for both engineering and mechanical engineering. The role of an engineer as problem solver, innovator and creator was presented. The disciplines of engineering, such as chemical engineering and civil engineering were elaborated on. Areas of engineering practice, e.g., manufacturing, design, testing, were explained. Discussion was held on the skills and attributes needed for an engineering career. Specific attention was then turned to mechanical engineering. An automotive propulsion system was described via the technical areas of mechanical engineering: dynamics, heat transfer, fluid mechanics, etc. Finally, several examples of mechanical engineers in practice were discussed.

Hands-on Project: To further enhance the students' knowledge concerning engineering, articles from American Heritage of Invention and Technology were distributed for the students to read. After reviewing several back issues of this magazine the instructors chose the following articles on the basis on their interest and readability:

"Inside the Panama Canal" (Fall 1996)

"Thomas Edison, Failure" (Winter 1991)

"Amazing Light" (Spring 1992)

"Kettering" (Fall 1996)

"The History of the Zipper?" (Summer 1994)

Students were given about an hour to read an article and complete a worksheet that asked the student to provide some basic information about the article and the engineering involved in the article.

Homework Assignment: The students were asked to read a second article and complete the corresponding worksheet.

Lessons Learned: Though these are gifted middle school students neither their reading level nor attention level were up to carrying out the in-class or homework assignment. It might be better to have the students perform some world wide web searches concerning the activities of mechanical engineers.

\section{Unit 2 - Energy, Work and Heat}

Lecture Summary: Students were introduced to the concepts of energy, work, and heat. Types of energy were discussed and the methods to move energy were explained 
Hands-on Project: The students were asked to design and build a birthday candle boiler. The objective was given as: using the chemical energy of 12 birthday candles, create a device that will produce the most steam in 10 minutes. Two design considerations were stated: (i) maximize the conversion of chemical energy into thermal energy - maximize the burn rate and flame temperature (use the "right" amount of air) and (ii) maximize the heat transfer from the flame to the water (water captures most of the light leaving the candle). The students were provided with the following tools and supplies:

- Birthday Candles

- Matches

- Roll of Aluminum Foil

- Wire Coat Hangers

- Beaker

- Graduated Cylinder (can not be incorporated into the device)

- Ring Stand with Clamp

- Water

- Pair of Pliers/Wire Cutters (can not be incorporated into the device)

- Can of Play-Doh

Once the students had completed this design, build, and test project, they tested their devices against each other with the following competition procedure:

- Each team will fill their beaker with $50 \mathrm{ml}$ of cold water

- At the go signal the team will light their candles

- At the stop signal (10 minutes later) the team will blow out their candles and remove the beaker with the remaining water from their device

- The remaining water is poured into the graduated cylinder for measurement

- The amount of water boiled is the difference between the $50 \mathrm{ml}$ at the beginning and the measurement at the end

- Each instance of accidental spillage will deduct $10 \mathrm{ml}$ from the amount boiled

- For intentional spillage, the team will be disqualified.

- Should any team boil off all of their water during the competition the time of this occurrence will be recorded

- The wining team will be determine as the team with the largest ratio of amount of water boiled to trial time

The best device produced a boiling rate of $3.8 \mathrm{ml} / \mathrm{min}$, while most devices were in the range of 2-3 $\mathrm{ml} / \mathrm{min}$.

Homework Assignment: As homework the students were asked to take the performance results of their device and calculate the energy produced by the candles, the energy absorbed by the water, and energy conversion efficiency

Lessons Learned: The hands-on project turned out to be considerably dirty due to the soot produced by the candles and required additional cleanup time. Also one student was scalded by hot water when their beaker was knocked over, leading the instructional team to become more 
aware of safety issues. The project was significantly complicated, so as to probably be a bad choice for the first hands-on project.

\section{Unit 3 - Design as a Creative Problem Solving Process and Structures}

Lecture Summary: The students were introduced to the idea of design as a creative problem solving process. Some historical examples of the design process, such as Edison's invention of the light bulb were presented. The traditional steps in the design process were then discussed. The second part of the lecture looked the use of structures in engineering, considering the two main components of support and stability. Examples of structures such as skyscrapers, bridges and roller coasters were shown.

Hands-on Project: The students were asked to design and build a straw structure. The objective was given as: using drinking straws and masking tape, create a structure that will hold a can of soda as high as possible. Two design considerations were stated: (i) maximize the height without the structure collapsing and (ii) maximize the height without the structure falling over. The students were provided with the following tools and supplies:

- 1 Box of Straws (only straws are to be used, not the box)

- 1 Roll of Masking Tape

- 2 Pairs of Scissors (can not be incorporated into the structure)

- 1 Can of Soda

Once the students had completed this design, build, and test project, they tested their devices against each other with the following competition procedure:

- Each team will collect their tools and supplies

- At the start signal the team will have 45 minutes to design and build

- At the stop signal the team is to halt construction

- The height of the bottom of the soda can will be measured

- The wining team will be determine as the team with the greatest height

- The structure may be anchored to the floor, but neither the walls or ceiling can be used as supporting structures

The best device obtained a height of 40 inches, while most devices were about 30 inches in height.

Homework Assignment: There was no homework assignment for this unit.

Lessons Learned: For this unit the students' competitiveness went a little too far and they had to be reminded that the purpose of the unit was learning not winning or losing.

\section{Unit 4 - Buoyancy and Aerodynamics}

Lecture Summary: The students were introduced to the basic principles of buoyancy and aerodynamics with a focus on Archimedes' principle and the concept of lift.

Hands-on Project: The students were asked to design and build a clay boat. The objective was given as: using the clay provided, create a boat that will hold as many pennies as possible. The 
design consideration of applying Archimedes' principle was stated. The students were provided with the following tools and supplies:

- 1 Hunk of Clay

- 1 Testing Tank

- Rolling Pin

- Pennies

- Water

Once the students had completed this design, build, and test project, they tested their devices against each other with the following competition procedure:

- Each team will collect their tools and supplies

- At the start signal the team will have 45 minutes to design and build

- At the stop signal the team is to halt construction

- The empty boat will be placed in the tank

- Pennies will be added to the boat until it sinks

- The winning team will be determined as the team whose boat holds the most pennies before it sinks

The best device held 104 pennies, while most devices held between 70-90 pennies.

Homework Assignment: As homework the students were asked to take the performance results of their device and calculate the number of pennies their boat should hold and compare this with the actual number of pennies their boat held.

Lessons Learned: Even though the clay used was oil based, if it got too wet during testing it became unusable.

\section{Unit 5 - Heating and Air Conditioning}

Lecture Summary: The students were taught the importance of controlling temperature and relative humidity in the thermal environment. Heating and air conditioning systems were discussed. A demonstration experiment using a vacuum chamber showed the relationship between boiling temperature and pressure. This was used to demonstrate how a vapor compression refrigeration system works.

Hands-on Project: The hands-on project consisted of a tour of the HVAC system for the Engineering Building on the MSU campus. The students were shown the radiant steam heating system used in the classroom, the absorption refrigeration system located in the building's basement, the air handling and cooling system located in the penthouse mechanical room, and the cooling tower located on the roof. Also from the roof the students could see the campus steam power plant that supplies the steam for the radiant heating and absorption refrigeration systems.

Homework Assignment: For the homework assignment the students were introduced to the saturation temperature/pressure relationships for Refrigerant-134a and Refrigerant-12. For each 
refrigerant they calculated the compressor work required for specified operating pressures. The students were asked to discuss the environmental considerations of the increased work required for Refrigerant-134a in light of Refrigerant-12's impact on the ozone layer.

Lessons Learned: It was very important to thoroughly prep the students for the tour, as the noise level was significant.

\section{Unit 6 - Propulsion}

Lecture Summary: The students were introduced to a variety of propulsion systems used on land, water, and in the air. It was noted that almost all propulsion systems work by converting chemical energy either into work (wheels or propellers turning) or kinetic energy (high velocity fluid streams)

Hands-on Project: The students were asked to design and build a baking soda and vinegar propulsion system. The objective was given as: using a minimum amount of baking soda and vinegar, inflate a balloon to the greatest extent possible. Three design considerations were stated: (i) determine how to conduct the test, (ii) determine the best combination or ratio of baking soda and vinegar, and (iii) minimize the amount of baking soda and vinegar needed to inflate the balloon. The students were provided with the following tools and supplies:

- 4 Balloons

- 116 oz Package of Baking Soda

- 1 pint Container of Vinegar (refillable once)

- Glass Flask

- Graduated Cylinder

- Electronic Scale

- Spatula

Once the students had completed this design, build, and test project, they tested their devices against each other with the following competition procedure:

- Each team will collect their tools and supplies

- At the start signal the team will have 45 minutes to design and build

- At the stop signal the team is to halt construction

- The desired amount of vinegar will be measured and recorded

- The desired amount of baking soda will measured and recorded

- The reaction will be allowed to take place

- When gas production ceases, the height of the balloon will be measured

- Each team will be ranked with respect to height (high to low), amount of baking soda used (low to high), and the amount of vinegar used (low to high)

- Points will be assigned for each ranking, 5 pts for $1^{\text {st }}, 4$ for $2^{\text {nd }}, 3$ for $3^{\text {rd }}, 2$ for $4^{\text {th }}, 1$ for $5^{\text {th }}$

- The points for each ranking will be added and the winning team will be the one with the most points

The best device expanded the balloon to a diameter 9.75 inches using 20.3 grams of baking soda and $250 \mathrm{ml}$ of vinegar. 
Homework Assignment: There was no homework assignment for this unit.

Lessons Learned: Initially all three components of the design, balloon height, amount of baking soda used, and the amount of vinegar used, were equally weighted. It was found that the competition ran better when the height was weighted twice the other two components. Allowing the students to develop their own test procedure seemed to be a very positive discovery experience for them.

\section{Unit 7 - Dynamics}

Lecture Summary: Students were taught that motion can be described with the use of position, velocity, and acceleration. Then Newton's laws of mechanics were presented.

Hands-on Project: The students were asked to design and build a popsicle stick slingshot. The objective was given as: using the popsicle sticks and rubber bands provided, build a ground level launching slingshot that will propel the plastic ball as far as possible. Three design considerations were stated: (i) convert as much of the rubber band energy as possible into kinetic energy of the ball, (ii) have a strong enough structure to support the force of the rubber band, and (iii) best possible way to launch the ball. The students were provided with the following tools and supplies:

- 1 Plywood Base

- 2 Rubber Bands

- 1 Roll of Masking Tape

- 2 Plastic Balls

- Tape Measure

Once the students had completed this design, build, and test project, they tested their devices against each other with the following competition procedure:

- Each team will collect their tools and supplies

- At the start signal the team will have 45 minutes to design and build

- At the stop signal the team is to halt construction

- The class will then go outside for the competition

- Each team will have two attempts to propel the plastic ball

- The greater of the two distances will be recorded

- The winning team will be the one with the greatest distance

The best device propelled the ball $39 \mathrm{ft} 6$ in, with most devices propelled the ball between $12 \mathrm{ft}$ and $30 \mathrm{ft}$.

Homework Assignment: There was no homework assignment for this unit.

Lessons Learned: One team attempted to build a catapult, rather than a slingshot, which proved very unsuccessful. Due to the fact that the device was used for the next unit, this team was allowed to rebuild their device. 


\section{Unit 8 - Controls}

Lecture Summary: The students were introduced to different types of controls, such as calibration, mechanical, electrical, and microprocessor.

Hands-on Project: The students were asked to calibrate the popsicle stick slingshot built in unit 7. The objective was given as: calibrate the popsicle stick slingshot to deliver the plastic ball closest to a target.. Three design considerations were stated: (i) calibrate with respect to launch angle, (ii) calibrate with respect to "pull-back" distance, and (iii) reproducibility, The students were provided with the following tools and supplies:

- Popsicle Stick Slingshot

- Ruler

- Protractor

- 2 Plastic Balls

- Tape Measure

Once the students had completed their calibration, they tested their devices against each other with the following competition procedure:

- Each team will collect their tools and supplies

- The class will then go outside for the project

- At the start signal the team will have 45 minutes to calibrate their slingshot

- At the stop signal the team is to halt calibration

- Each team will have one attempt to propel the plastic ball at a target

- The distance the ball lands away form the target will be recorded

- The target will be moved and the process repeated

- The distances away for each target will be added and the winning team will be the one with the smallest total distance

The best device propelled the ball within 3 inches of the target, while most devices propelled the ball between $2 \mathrm{ft}$ and $3 \mathrm{ft}$ of the target.

Homework Assignment: There was no homework assignment for this unit.

Lessons Learned: Students observed that the performance of their slingshot would degrade over use.

\section{Units 9 and 10 - Manufacturing}

Lecture Summary: The students were introduced to the three main processes of manufacturing: materials processing, fastening, and forming. The assembly line process was then discussed, including parallel and series processing paths.

Hands-on Project: For unit 9 the students were asked to design an assembly line to produce a Beanie Eel toy. The objective was given as: using the materials, tools, and process descriptions provided design an assembly line that will produce six Beanie Eels as quickly as possible.. Two design considerations were stated: (i) determine which processes should be in parallel and which in series and (ii) determine how personnel and tools are to be utilized. The students were provided with the following tools and supplies: 
- $714 "$ x 16" Swatches of Cloth

- 2 Pairs of Scissors

- 1 Beanie Eel Cardboard Pattern

- 3 Staplers

- 2 Permanent Markers

- 4 Bags of Dried Spilt Peas

- 1 Styrofoam Cup

Once the students had completed this design, build, and test project, they tested their assembly lines against each other with the following competition procedure:

- Each team will collect their tools and supplies

- At the start signal the team will have 45 minutes to design their assembly line and test with production of one (1) Beanie Eel

- At the stop signal the team is to halt their design and organization

- With all the manufacturing stations staffed and the assembly line ready production will begin

- Each team will assemble six (6) Beanie Eels

- Students may not change manufacturing stations unless it is in their plan

- The team that completes production in the shortest time with all Beanie Eels passing inspection will win the competition.

The best assembly line produced six Beanie Eels in 13 min $10 \mathrm{sec}$, with most assembly lines taking between 14 to 20 minutes.

For unit 10 a tour of the General Motors final assembly plant in Lansing was taken, so the students could see an actual assembly line in process.

Homework Assignment: There were no homework assignments for these units.

Lessons Learned: The class instructors served the important function of quality inspection for the assembly lines. It was found that spilt split peas require a considerable cleanup effort. The quality of tour was greatly dependent on the tour guide.

\section{Conclusions}

Reaction from the students were very positive. The standard format proved successful in keeping most of the students focused and involved. The MST administrative staff conducted an exit survey of the participants. For each academic class the students were asked to rate how much they learned. For mechanical engineering the responses were as follows:

Learned a lot:

Learned some new information:

Learned very little:
$17(53.1 \%)$

$15(46.9 \%)$

$0(0 \%)$ 
These numbers were very consistent with most of the other academic classes. In fact, at the first meeting for the MST 2000 program, the other academic classes were encouraged by the program administration to adopt a more project, hands-on approach to their teaching. The supply budget for the projects was just under $\$ 300$. It is recommended that this type of program could be run in middle schools during the academic year, perhaps doing a unit a week and utilizing undergraduate mechanical engineering students to supervise the projects at the middle school.

CRAIG W. SOMERTON

Craig W. Somerton is an Associate Professor of Mechanical Engineering at Michigan State University. He teaches in the area of thermal engineering including thermodynamics, heat transfer, and thermal design. Dr. Somerton has research interests in computer design of thermal systems, transport phenomena in porous media, and application of continuous quality improvement principles to engineering education. He received his B.S. in 1976, his M.S. in 1979, and his Ph.D. in 1982, all in engineering from UCLA.

TERRY L. BALLINGER

Terry L. Ballinger is a Chemistry and Math Teacher at Lansing Catholic Central High School. Mr. Ballinger has a B.S. in 1981 from Central Michigan University with a chemistry major and math minor. He has been an active participant in hands-on science workshops including AIMS, Operation Physics, LEAD, and the U of M Biological Station. 